\title{
PENGARUH PENGGUNAAN MEDIA AUDIO VISUAL TERHADAP MOTIVASI DAN HASIL BELAJAR SISWA PADA BIDANG STUDI SEJARAH DI MTS DAARUL MUTTAQIIN JOTANG
}

\author{
Djamal Effendi \\ Pendidikan Sejarah, SMK N 1 Sumbawa, Djamal.efendi@gmail.com
}

\section{INFO ARTIKEL}

RiwayatArtikel:

Diterima: 07-04-2017

Disetujui: 06-05-2017

\section{Kata Kunci:}

1. Media

2. Audio Visual

\begin{abstract}
ABSTRAK
Mengetahui Pengaruh Penggunaan Media Audio Visual Terhadap Motivasi Dan Hasil Belajar Siswa Kelas VIII Pada Bidang Studi Sejarah Di Mts Daarul Muttaqiin Jotang. Metode yang digunakan adalah Metode eksperimen dengan tehknik pengumpulan data menggunakan tehknik tes, wawancara, dan dokumentasi. Dengan jumlah sampel 34 siswa yang terdiri dari dua kelas, kelas A 20 orang dan kelas B 14 orang.

Analisis data diperoleh nilai pre-tes kelas kontrol 49.73 dan nilai pos-tes 65.79, sedangkan nilai pre-tes kelas eksperimen adalah 61.62 dan nilai pos-tes 78.62 . Untuk nilai $\mathrm{F}$ dengan taraf signifikansi 0.05 maka didapat F-tabel (1.82) dan rhitung 1.468. jadi bisa dikatakan kalau kedua kelas tersebut adalah homogen dan dapat dijadikan kelas penelitian. Sedangkan untuk nilai tes akhir dari kelas eksperimen adalah diketahui $r_{\text {hitung }} 7.828$ sedangkan $r_{\text {tabel }} 1.671$, dengan demikian terdapat prestasi belajar siswa kelas VIII pada bidang studi sejarah di MTs Daarul Muttaqiin jotang kerena memperoleh nilai $r_{\text {hitung }}>r_{\text {tabel, }}$ oleh karena itu terdapat Pengaruh Media Audio Visual Terhadap Motivasi Dan Hasil Belajar Siswa Kelas VIII Pada Bidang Studi Sejarah di MTs Daarul Muttaqiin jotang.

Abstract: Knowing The Effect Of Using Audio Visual Media To The Motivation And Student Result Of Class VIII In The Field Of History Of History In Mts Daarul Muttaqiin Jotang. The method used is experimental method with tehknik data collection using tehknik test, interview, and documentation. With a sample size of 34 students consisting of two classes, A class 20 people and class B 14 people.

Data analysis obtained 49.73 control grade pre-test grade and post-test value of 65.79, while experiment class pre-test value is 61.62 and post-test value 78.62. For $F$ value with significance level of 0.05 then get F-table (1.82) and rhitung 1.468. so it can be said that both classes are homogeneous and can be used as research class. As for the final test score of the experimental class is known to rhitung 7,828 while rtabel 1.671, thus there is a learning achievement of class VIII students in the field of history studies in MTs Daarul Muttaqiin jotang get rcount $>$ rtabel, therefore there is Influence of Audio Visual Media Against Motivation And Student Results Class VIII On Field Study History in MTs Daarul Muttaqiin jotang.
\end{abstract}

\section{A. LATAR BELAKANG}

Dalam keseluruhan proses pendidikan di sekolah, kegiatan belajar merupakan kegiatan yang paling pokok. Ini berarti bahwa berhasil tidaknya pencapaian tujuan pendidikan banyak bergantung kepada bagaimana proses belajar yang dialami oleh siswa sebagai anak didik (Slameto, 2003:1).

Dalam kegiatan pembelajaran, peran seorang guru harus dapat mengetahui karakteristik dan faktor-faktor yang mempengaruhi belajar siswa, misalnya motivasi siswa terhadap pembelajaran sehingga tujuan pembelajaran yang telah ditetapkan dapat tercapai secara cepat, efektif, dan efesien. Siswa seringkali mengalami kejenuhan dan kebosanan selama mengikuti proses pembelajaran dikarenakan proses belajar-mengajar terjadi secara menoton.

Seyogyanya proses belajar-mengajar ini, peserta didik harus secara aktif dan mendapatkan perhatian penuh dari siswa selama mengikuti proses pembelajaran, sehingga tujuan pembelajaran dapat tercapai. Dalam hal ini, peranan seorang guru sangat penting dalam memperhatikan dan menciptakan kondisi-kondisi dimana memungkinkan siswa belajar sehingga dapat mencapai tujuan dari proses pembelajaran, yaitu adanya perubahan dari tingkah laku siswa.

Berdasarkan pendapat di atas, peneliti dapat menyimpulkan bahwa dalam proses pembelajaran sejarah kehadiran media memiliki arti yang cukup penting. Mengingat selama ini hasil dari pembelajaran sejarah 
dinilai masih kurang, Karena para guru kurang memperhatikan komponen-komponen lain yang dapat membantu proses pembelajaran, diantaranya metode mengajar yang digunakan masih monoton. Contohnya seperti metode ceramah.

Tanpa menggunakan media yang dapat memberikan gambaran lebih konkrit tentang materi yang disampaikan. Sehingga seringkali tujuan dari pembelajaran belum bisa tercapai dengan maksimal. Latuheru (2000:14), menyatakan bahwa media pembelajaran adalah bahan, alat, atau teknik yang digunakan dalam kegiatan belajar mengajar dengan maksud agar proses interaksi komunikasi edukasi antara guru dan siswa dapat berlangsung secara tepat guna dan berdaya guna. Berdasarkan definisi tersebut, media pembelajaran memiliki manfaat yang besar dalam memudahkan siswa mempelajari materi pelajaran. Oleh karena itu salah satu cara untuk meningkatkan belajar siswa adalah dengan memanfaatkan media pembelajaran. Dengan memanfaatkan media tersebut proses belajar mengajar di kelas menjadi menarik dan menyenangkan.

\section{B. METODE PENELITIAN}

Penelitian ini akan menggunakan pendekatan kuantitatif. Karena data atau informasi yang penulis kumpulkan dalam penelitian ini yang memerlukan perhitungan dengan berbentuk kuantitatif yang menggunakan angka-angka statistik dalam proses analisis data. Data-data yang diperoleh peneliti di lapangan berupa angka-angka yang akan diproses dengan cara menghimpun, mengatur, menyusun, mengolah, mengkaji. Kemudian melalui proses di atas, barulah dapat ditarik kesimpulan.

Berdasarkan populasi penelitian adalah keseluruhan siswa kelas VIII MTs Daarul Muttaqiin Jotang berjumlah 34 orang. Teknik pengambilan sampel dalam penelitian ini adalah teknik propesional random samling yaitu pengambilan sampel pada populasi yang berdasarkan wilayah atau kelompok yang diterapkan secara seimbang atau sebanding. (suharsimi A, 2006 ;112), dimana pengambilan sampel diambil dengan undian, maka setiap anggota populasi diberi nomor terlebih dahulu sesuai dengan jumlah anggota populasi. Dengan demikian, sampel dalam penelitian adalah $100 \%$ dari total populasi yaitu 34 orang. Jadi jumlah sampel yang diambil dalam penelitian ini adalah 34 orang siswa.

Adapun yang menjadi variabel dalam penelitian ini adalah sebagai berikut:

a. Variabel bebas dalam penelitian ini adalah media audio visual

b. Variabel terikat dalam penelitian ini adalah motivasi dan hasil belajar

Adapun metode pengumpulan data yang digunakan yaitu observasi, wawancara, metode tes dan dokumentasi. Untuk analisis penelitian yang menggunakan pendekatan kuantitatif sesuai dengan masalah yang diteliti dalam peneliti dalam penelitian ini yaitu : " pengaruh penggunaan media audio viasual terhadap motivasidan hasil belajar kelas VIII pada bidanng studi sejarah di MTs daarul muttaqiin jotang", maka peneliti menggunakan analisis statistik yaitu denngan t-tes. Adapun format yang digunakan adallah sebagai berikut;

Rumus

$$
t=\frac{\bar{X}_{1}-\bar{X}_{2}}{\sqrt{\frac{\left(n_{1}-1\right) S_{1}^{2}+\left(n_{2}-1\right) S_{2}^{2}}{n_{1}+n_{2}-2}\left(\frac{1}{n_{1}}+\frac{1}{n_{2}}\right)}}
$$

Keterangan :

$\mathrm{X}_{1}=$ nilai rata-rata dari kelas eksperimen

$\mathrm{X}_{2}=$ nilai rata-rata dari kelas kontrol

$\mathrm{S}_{1}=$ standar deviasi kelas eksperimen

$\mathrm{S}_{2}=$ standar deviasi kelas kontrol

$\mathrm{N}_{1}=$ jumlah sampel kelas eksperimen

$\mathrm{N}_{2}=$ jumlah sampel kelas kontrol

Kriteria pengujian :

- Jika $t_{\text {hitung }}>t_{\text {tabel }}$ maka hipotesisi alternatif (Ha) diterima dan hipotesis (Ho) di tolak.

- Jika $t_{\text {hitung }}<t_{\text {tabel }}$ maka hipotesis alternatif (Ha) ditolak dan hipotesis (Ho) diterima. (Sugiyono 2005: 48).

Formalitas tersebut di atas akan digunakan untuk menyelsaikan hasil dari innstrumen hasil tes yang dikembangkan sendiri oleh peneliti. Sedangkan analisis pendekatan kuanlitatif, peneliti menggunakan analisis 
induktif, dimana dimana peneliti akan mendeskripsikan ataupun menggunakan setiap iitem butir pertanyaan atau pertanyaan yang disajikan untuk pedoman dalam menggali permasalahan.

\section{HASIL DAN PEMBAHASAN}

Untuk menggambarkan data lapangan yang telah dikumpulkan dari responden tentang penggunaan media audio visual serta pengaruhnya terhadap motivasi dan hasil belajar siswa kelas VIII pada bidang studi sejarah di MTs Daarul Muttaqiin Jotang, maka dalam sub bab ini data dideskripsikan sebagai berikut :

Tabel. 1 Deskripsi Nama Sampel Dalam Penelitian

\begin{tabular}{|c|c|c|}
\hline No & Nama & Jenis kelamin \\
\hline 1. & Abdul aji & $\mathrm{L}$ \\
\hline 2. & Aida nashifatulnufus & $\mathrm{P}$ \\
\hline 3. & Angrikurniawansyah & $\mathrm{L}$ \\
\hline 4. & Ardiansyah & $\mathrm{L}$ \\
\hline 4. & Ari ade kantari & $\mathrm{P}$ \\
\hline 6. & Ari nadia & $\mathrm{P}$ \\
\hline 7. & Awali septi ariani & $\mathrm{P}$ \\
\hline 8. & Amin rais & $\mathrm{L}$ \\
\hline 9. & Ariansyah & $\mathrm{L}$ \\
\hline 10. & Edel wisita & $\mathrm{P}$ \\
\hline 11. & Eva wardani & $\mathrm{P}$ \\
\hline 12. & Fajar maharda putra & $\mathrm{L}$ \\
\hline 13. & Febri akhirul akbar & $\mathrm{L}$ \\
\hline 14. & Firmansyah & $\mathrm{L}$ \\
\hline 15. & Fitri wulandari & $\mathrm{P}$ \\
\hline 16. & Heriyansyah & $\mathrm{L}$ \\
\hline 17. & Jefri maolana zakki & $\mathrm{L}$ \\
\hline 18. & Kafta fuad alamsyah & $\mathrm{L}$ \\
\hline 19 & Khaerul hasandi & $\mathrm{L}$ \\
\hline 20. & Leni wahyuningsih & $\mathrm{P}$ \\
\hline 21. & M . rizal gamazzy & $\mathrm{L}$ \\
\hline 22. & Mega aulia syahra & $\mathrm{P}$ \\
\hline 23. & Noer jannah sabdah R. & $\mathrm{P}$ \\
\hline 24. & Novita wahyu listari & $\mathrm{P}$ \\
\hline 25. & Nur aini & $\mathrm{P}$ \\
\hline 26. & Nur hazisah & $\mathrm{P}$ \\
\hline 27. & Ramdani akbar & $\mathrm{L}$ \\
\hline 28. & Roni rosadi & $\mathrm{P}$ \\
\hline 29. & Roni saputra & $\mathrm{L}$ \\
\hline 30. & Rosdiana & $\mathrm{P}$ \\
\hline 31. & Rudi supriadi & $\mathrm{L}$ \\
\hline 32. & Sanubi & $\mathrm{L}$ \\
\hline 33. & Sara anjani & $\mathrm{P}$ \\
\hline 34. & Sri wahyuni & $\mathrm{P}$ \\
\hline
\end{tabular}

Sumber data : MTs Daarul Muttaqiin Jotang

Dalam pengambilan data di lapangan ada dua

metode yang digunakan yaitu dengan metode wawancara dan metode tes. Metode wawancara yaitu berisi tentang penggunaan Media Audio Visual, dimana terdiri dari 20 pertanyaan.
Untuk mengetahui motivasi dan hasil belajar siswa setelah pelaksanaan pembelajaran menggunakan Media Audio Visual, diadakan tes yang terdiri dari 20 soal pilihan ganda (multipel choict) a,b,c,dan d yang diambil dari materi sejarah (perang Dunia I dan Perang Dunia II ). Dari 20 soal yang diberikan kepada responden, setiap soal memiliki skor yang sama, dimana apabila responden menjawab benar, maka akan memperoleh skor 1 dan apabila menjawab salah maka responden mendapat skor 0 .

\section{Prestasi Belajar Siswa Sejarah}

Dalam penyajian ini peneliti memaparkan nilai tes awal (pre tes) dan tes akhir (pos tes). Adapun data nilai tes awal dan tes akhir tersebut dapat di lihat pada tabel berikut :

Tabel 2. nilai pretes kelas eksperimen dan kelas kontrol

\begin{tabular}{|c|c|c|c|}
\hline No & Kelas eksperimen & No & Kelas kontrol \\
\hline 1. & 50 & 1. & 65 \\
\hline 2. & 45 & 2. & 45 \\
\hline 3. & 35 & 3. & 45 \\
\hline 4. & 60 & 4. & 55 \\
\hline 5. & 55 & 5. & 70 \\
\hline 6. & 60 & 6. & 50 \\
\hline 7. & 70 & 7. & 35 \\
\hline 8. & 65 & 8. & 35 \\
\hline 9. & 70 & 9. & 35 \\
\hline 10. & 55 & 10. & 35 \\
\hline 11. & 55 & 11. & 50 \\
\hline 12. & 35 & 12. & 35 \\
\hline 13. & 65 & 13. & 35 \\
\hline 14. & 75 & 14. & 45 \\
\hline 15. & 35 & 15. & 35 \\
\hline 16. & 70 & 16. & 55 \\
\hline 17. & 75 & 17. & 60 \\
\hline 18. & 60 & 18. & 45 \\
\hline 19. & 50 & 19. & 75 \\
\hline 20. & 60 & 20. & 35 \\
\hline 21. & 65 & 21. & 35 \\
\hline 22. & 70 & 22. & 35 \\
\hline 23. & 75 & 23. & 45 \\
\hline 24. & 70 & 24. & 65 \\
\hline 25. & 45 & 25. & 45 \\
\hline 26. & 60 & 26. & 40 \\
\hline 27. & 65 & 27. & 35 \\
\hline 28. & 55 & 28. & 70 \\
\hline 29. & 65 & 29. & 55 \\
\hline 30. & 70 & 30. & 50 \\
\hline 31. & 75 & 31. & 55 \\
\hline 32. & 75 & 32. & 50 \\
\hline 33. & 60 & 33. & 65 \\
\hline 34. & 65 & 34. & 75 \\
\hline $\mathrm{N}$ & 34 & $\mathrm{~N}$ & 34 \\
\hline$X$ & 61.62 & $X$ & 49.73 \\
\hline $\mathrm{S}$ & 5.67 & $\mathrm{~S}$ & 5.66 \\
\hline
\end{tabular}




\begin{tabular}{|c|c|c|c|}
\hline $\mathrm{S}^{2}$ & 32.01 & $\mathrm{~S}^{2}$ & 32.04 \\
\hline
\end{tabular}

Sumber data : MTs Daarul Muttaqiin Jotang

Berdasarkan data pada tabel di atas, diperoJeh nilai rata-rata standar deviasi dan varian dari nilai tes awal dan tes akhir untuk kelas eksperimen dan kelas kontrol adapun perhitungan. a. Distribusi frekuensi nilai pre-tes kelas eksperimen

$$
\begin{aligned}
\bar{X} & =\frac{\sum X_{2}-F_{i}}{\sum F_{i}} \\
& =\frac{2083}{34}
\end{aligned}
$$

Setelah mencari nilai rata-rata maka dilanjutkan dengan mencari nilai varian dan simpangan baku, adapun perhitungannya:

$$
\begin{aligned}
\mathrm{S}^{2} & =\sqrt{\frac{\sum\left(X_{1}-X\right)^{2}}{n-1}} \\
& =\sqrt{\frac{1056}{34-1}} \\
& =\sqrt{32,01} \\
& =5,67
\end{aligned}
$$

$>$ Mencari simpangan baku (S2)

$$
\begin{aligned}
S^{2}= & \frac{\left(X_{1}-X\right)^{2}}{n-1} \\
& =\frac{1056,2}{34-1} \\
& =32,01
\end{aligned}
$$

b. Distribusi frekuensi nilai pre-tes kelas kontrol

$$
\begin{aligned}
\bar{X} & =\frac{\sum X_{2}-F_{i}}{\sum F_{i}} \\
& =\frac{1691}{34} \\
& =49,73
\end{aligned}
$$

Setelah mencari nilai rata-rata maka dilanjutkan dengan mencari nilai varian dan simpangan baku, adapun perhitungannya:

Mencari varians $\left(\mathrm{S}^{2}\right)$

$$
\begin{aligned}
S^{2} & =\sqrt{\frac{\sum\left(X_{1}-X\right)^{2}}{n-1}} \\
& =\sqrt{\frac{1057,24}{34-1}} \\
& =\sqrt{32,04} \\
& =5,66
\end{aligned}
$$

$>\quad$ Mencari simpangan baku (S2)

$$
\mathrm{S}^{2}=\frac{\left(X_{1}-X\right)^{2}}{n-1}
$$

$$
\begin{aligned}
& =\frac{1057,42}{34-1} \\
& =32,04
\end{aligned}
$$

2. Analisis Data

a. Uji Homogenitas

Dalam analisis data ini peneliti memaparkan perolehan nilai uji homogenitas kedua kelas. Berdasarkan data pada tabel (4) diperoleh nilai rata-rata untuk kelas eksperimen adalah 61,62 dan kelas kontrol adalah 49,73. Sedangkan variansnya untuk kelas eksperimen adalah 32,01 dan untuk kelas kontrol adalah 32,04.

Dari nilai varians (simpangan) di atas kemudian dimasukkan ke dalam rumus uji $F$ yaitu :

$$
\begin{aligned}
& F=\frac{\text { Varian Terbesar }}{\text { Varian Terkecil }} \\
& =\frac{32,04}{32,01}=1,468
\end{aligned}
$$

Dari kriteria untuk F-tabel dk. Pembilang $(n-1)=$ (34-1) dan dk. penyebut $(b-1)=(34-1)$. Dengan taraf signifikansi $a=0,05$ maka, didapat $F$ - tabel $(1,82)$, jika dibandingkan antara $F$-hitung dengan $F$ - tabel maka $F$ hituung lebih besar dari pada $F$-tabel $(1,468>1,82)$. Jadi bisa dikatakan kalau kedua kelas tersebut adalah homogen dan bisa dijadikan sebagai kelas penelitian karena mempunyai karakteristik yang sama (homogenitas).

b. Uji hipotesis (uji-t)

Dari hasil tes akhir yang diberikan kepada dua kelas yaitu kelas eksperimen maupun kelas kontrol diperoleh hasil uji t (uji hipotesis) adalah t-hitung $==7,828$ dan tabel 2,000 pada taraf signifikansi (a) $=5 \%$

Dalam menjawab permasalahan yang digunakan dalam penelitian ini data dianalisa dengan uji $t$ ( $t$-tes) ini berguna untuk menentukan ada tidaknya peningkatan prestasi belajar antara kelas eksperimen (kelas yang diterapkan media audio visual). Adanya perhitungan dari uji $t$ (uji hipotesis) adalah:

$$
\mathrm{t}=\frac{\mathrm{X} 1-\mathrm{X} 2}{(n 1-1+(n 2-1) \mathrm{S} 2}
$$

Dari $t$ - hitung tersebut lalu dibandingan dengan $t$ tabel. Dengan kriteria pengujian untuk uji $t$ adalah jika $t$ hitung $>t$-tabel pada taraf signifikansi 5\% dengan derajat kebebasan $(\mathrm{dk}) n 1-n 2=66$ diperoleh $t$-tabel = 1,671.

Dari perolehan nilai di atas dapat disimpulkan bahwa ada perbedaan yang disignifikansi antara kelas yang diterapkan audiio visuall (kelas eksperimen) dengan 
kelas yang tidak diterapkan audio visual (kelas kontrol). Dengan demikian terdapat prestasi belajar sejarah siswa kelas VIII MTs Daarul Muttaqiin Jotang pada pokok pembahasan pada perang dunia I dan II. Karena memperoleh t-hitung (7.828) $\geq \mathrm{t}$ - tabel (1.671), ini berarti hipotesis alternatifnya (Ha) diterima dan (Ho) ditolak.

\section{Uji validitas}

Uji validitas yaitu digunakan untuk menguji validitas butir-butir instrumen yang dianalisis dengan analisis item dengan menggunakan rumus produk moment.

$$
r_{x y}=\frac{\sum X Y-\left(\sum X\right)\left(\sum Y\right)}{\sqrt{\left\{N \sum x^{2}-\left(\sum X\right)^{2}\right\}\left\{N \sum Y^{2}-\left(\sum Y\right)^{2}\right\}}}
$$

Berdasarkan hasil perhitungan uji validitas di atas dengan harga $r_{\text {hitung }} 0.339$ dengan taraf signifikan 95\%, dapat disimpulkan bahwa instrumen soal no 1, 7, 8, dan 11 tidak valid maka instrumen soal diganti dengan soal lain dapat digunakan dan dapat dikatakan valid, dan dapat digunakan lebih lanjut.

4.3.4. uji relibilitas

Uji reliabilitas instrumen digunakan untuk mengetahui reliabilitas intrumen. Intrumen dikatakan riabel adalah instrumen yang bila digunakan beberapa kali untuk mengukur obyek yang sama akan menghasilkan data yang sama (Suharsimi Arikunto, 2010:221). Dallam penelitian ini, untuk mencari reliabilitas menggunakann rumus KR-20, sebagai berikut:

$$
\mathrm{R}_{11}=\frac{k}{k-1}\left\lfloor\frac{V t-\sum P q}{V t}\right\rfloor
$$

Keterangan :

$$
\begin{array}{ll}
\mathrm{R}_{11} & =\text { Reliabilitas } \\
\mathrm{K} & =\text { banyaknya butir soal } \\
\mathrm{Vt} & =\text { varians soal } \\
\mathrm{P} & =\underline{\text { banyaknya subyek yang skornya } 1} \\
\mathrm{~N} & =\underline{\text { banyaknya subyek yang skor nya nol }} \\
& \quad(\mathrm{q}=1-\mathrm{p})
\end{array}
$$

Hasil perhitungan dikonsultasikan dengan tabel taraf signifikan 95\%. Untuk mengetahui tinggi rendahnya koefisien kemudian hasilnya dikonsultasikan dengan menggunakan interpretasi terhadap koevisien yaitu: Antara 0.600 sampai dengan 1.00: sangat tinggi
Antara 0.400 sampai dengan 0.600: agak rendah Antara 0.00 sampai dengan 0.200 : sangat rendah Tabel : 3

\begin{tabular}{|l|l|l|l|}
\hline No soal & $\mathrm{P}$ & $\mathrm{Q}$ & $\mathrm{Pq}$ \\
\hline 1 & 0.9 & 0.1 & 0.09 \\
\hline 2 & 0.9 & 0.1 & 0.09 \\
\hline 3 & 0.9 & 0.1 & 0.09 \\
\hline 4 & 0.9 & 0.1 & 0.09 \\
\hline 5 & 0.7 & 0.3 & 0.21 \\
\hline 6 & 0.7 & 0.3 & 0.21 \\
\hline 7 & 0.8 & 0.2 & 0.16 \\
\hline 8 & 0.8 & 0.2 & 0.16 \\
\hline 9 & 0.7 & 0.3 & 0.21 \\
\hline 10 & 0.7 & 0.3 & 0.21 \\
\hline 11 & 0.6 & 0.4 & 0.24 \\
\hline 12 & 0.8 & 0.2 & 0.16 \\
\hline 13 & 0.8 & 0.2 & 0.16 \\
\hline 14 & 0.9 & 0.1 & 0.9 \\
\hline 15 & 0.7 & 0.3 & 0.21 \\
\hline 16 & 0.8 & 0.2 & 0.16 \\
\hline 17 & 0.8 & 0.2 & 0.16 \\
\hline 18 & 0.8 & 0.2 & 0.16 \\
\hline 19 & 0.6 & 0.4 & 0.24 \\
\hline 20 & 0.8 & 0.2 & 0.16 \\
\hline & & &
\end{tabular}

$\mathrm{Vt}=\frac{\sum x^{2}-\left(\begin{array}{c}\sum x^{2} \\ \mathrm{~N}\end{array}\right)}{N}=\frac{1156-(531) 2}{34}=\frac{1156-281.961}{34}=25.707$

Jadi untuk mencari $\mathrm{r}_{11}$ adalah sebagai berikut:

$\mathrm{R}_{11}=\frac{k}{k-1}\left\lfloor\frac{V t-\sum p q}{V t}\right\rfloor \frac{20}{20-1} \frac{25.707-3.26}{25.707}=\frac{22.447}{25.707}=0.8732$

Dengan nilai reliabilitas sebesar 0.8732 dapat dinyatakan bahwa tes hasil belajar untuik uraian tersebut sudah memiliki reliabilitas tes yang tinggi( $\mathrm{r}_{11}$ jauh lebih besar dari $r_{\text {tabel}}$ ) yaitu: $0.8732 \geq 0.364$. setelah itu hasil perhitungan dari $r_{11}$ dikonsultasikan dengan menggunakan interprestasi terhadap koefisien yaitu terdapat pada nilai 0.600 sampai 0.800 yang dinyatakan cukup. Dengan demikian dapat dikatakan instrumen penelitian sudah memiliki kualitas yang baik atau reliabilitas tinggi

\section{SIMPULAN DAN SARAN}

\section{Simpulan}

Dari hasil analisis data dan pembahasan tersebut di atas tentang "pengaruh penggunaan media audio visual terhadap motivasi dan hasil belajar siswa kelas VIII pada bidang studi sejarah di MTs Daarul Muttaqiin Jotang Tahun Pelajaran 2013/2014" maka dapat diberikan beberapa kesimpulan sebagai berikut: 
a) Diketahui nilai pre-tes kelas kontrol 49.73 dan nilai pos-tes 65.79, sedangkan nilai pre-tes kelas eksperimen adalah 61.62 dan nilai pos-tes 78.62 . Untuk nilai $\mathrm{F}$ dengan taraf signifikansi 0.05 maka didapat F-tabel (1.82) dan $\mathrm{r}_{\text {hitung }}$ 1.468. jadi bisa dikatakan kalau kedua kelas tersebut adalah homogen dan dapat dijadikan kelas penelitian. Sedangkan untuk nilai tes akhir dari kelas eksperimen adalah diketahui $\mathrm{r}_{\text {hitung }} 7.828$ sedangkan $r_{\text {tabel }} 1.671$, dengan demikian terdapat prestasi belajar siswa kelas VIII pada bidang studi sejarah di MTs Daarul Muttaqiin jotang tahun pelajaran 2013/2014 kerena memperoleh nilai $r_{\text {hitung }}>r_{\text {tabel. }}$

b) Terdapat Pengaruh Media Audio Visual Terhadap Motivasi Dan Hasil Belajar Siswa Kelas VIII Pada Bidang Studi Sejarah di MTs Daarul Muttaqiin jotang tahun pellajaran 20013/2014.

\section{Saran-Saran}

Sebagai penutup uraian dalam penelitian ini, maka perlu kiranya disampaikan suatu pendapat atau saran yang ditujukan pada peneliti sendiri maupun pihak lain yang berkompeten sehubungan dengan permasalan di atas. Adapun saran-saran yang dapat diberikan secara garis besar antara lain.

a) Kepada kepala sekolah MTs Daarul Muttaqiin Jotang, untuk menyediakan berbagai fasilitas mengajar seperti salah satunya LCD agar dapat membantu para guru dalam proses mengajar.

b) Kepada para guru di MTs Daarul Muttaqiin jotang untuk bisa mengetahui faktor-faktor apa saja yang bisa memotivasi siswa sehingga memudahkan mereka dalam memahami materi yang diajarkan.

c) Khususnnya kepada guru sejarah di MTs Daarul Muttaqiin Jotang, agar sebisa mungkin memilih media ajar yang bisa memotivasi siswa dalam belajar.

\section{DAFTAR RUJUKAN}

Afifuddin dan Beni Ahmad Saebani, 2009, Metodelogi Penelitian Kualitatif, Bandung: Pustaka Setia.

Arief S. Sadiman, dkk, 2006, Media pendidikan: Pengertian, Pengembangan, dan Pemanfaatannya, Jakarta : Raja Grafindo Persada.
Azhar Arsyad, 2005, Media Pembelajaran, Jakarta : Raja Grafindo Persada.

Mardalis, 2007, Metode Penelitian Suatu Pendekatan Proposal, Jakarta : PT Bumi Aksara.

Yudhi, Munadhi, 2012, Sebuah Pendekatan Baru, Jakarta : Gaung PersadaPress.

Sri Anitah, 2012, Media Pembelajaran, Surakarta: Yuma Pustaka.

Sugiono, 2012, Metode Penelitian Kuantitatif, Kualitatif dan R\&D, Bandung : Alfabeta.

Sukiman, 2012, Pengembangan Media Pembelajaran, Yogyakarta : Pustaka Insan Madani.

Burhan Bungin, 2007. Penelitian Kualitatif, Jakarta : Prenada Media grup

Sugiono. Dr. 2010. Metodologi Penelitian Kualitatif. Bandung : Penerbit Alfabeta.

http://id.wikipedia.org/wiki/Taman_Narmada

Sakdiah, 2002, pemanfaatan museum provinsi NTB sebagai media pembelajaran IPS sejarah (studi di man 2 mataram) 